Article

\title{
Species-Specific Impact of Fusarium Infection on the Root and Shoot Characteristics of Asparagus
}

\author{
Roxana Djalali Farahani-Kofoet, Katja Witzel, Jan Graefe, Rita Grosch $@$ and Rita Zrenner * \\ Plant-Microbe Systems, Leibniz Institute of Vegetable and Ornamental Crops (IGZ) e.V., 14979 Großbeeren, \\ Germany; kofoetr@igzev.de (R.D.F.-K.); Witzel@igzev.de (K.W.); graefe@igzev.de (J.G.); grosch@igzev.de (R.G.) \\ * Correspondence: zrenner@igzev.de
}

Received: 25 March 2020; Accepted: 22 June 2020; Published: 24 June 2020

check for updates

\begin{abstract}
Soil-borne pathogens can have considerable detrimental effects on asparagus (Asparagus officinalis) growth and production, notably caused by the Fusarium species F. oxysporum f.sp. asparagi, F. proliferatum and F. redolens. In this study, their species-specific impact regarding disease severity and root morphological traits was analysed. Additionally, various isolates were characterised based on in vitro physiological activities and on protein extracts using matrix-assisted laser desorption ionisation time-of-flight mass spectrometry (MALDI-TOF MS). The response of two asparagus cultivars to the different Fusarium species was evaluated by inoculating experiments. Differences in aggressiveness were observed between Fusarium species and their isolates on roots, while no clear disease symptoms became visible in ferns eight weeks after inoculation. F. redolens isolates Fred1 and Fred 2 were the most aggressive strains followed by the moderate aggressive F. proliferatum and the less and almost non-aggressive F. oxysporum isolates, based on the severity of disease symptoms. Fungal DNA in stem bases and a significant induction of pathogenesis-related gene expression was detectable in both asparagus cultivars. A significant negative impact of the pathogens on the root characteristics total root length, volume, and surface area was detected for each isolate tested, with Fred1 causing the strongest effects. No significant differences between the tested asparagus cultivars were observed.
\end{abstract}

Keywords: Fusarium oxysporum f.sp. asparagi; Fusarium proliferatum; Fusarium redolens; MALDI-TOF MS; morphology imaging; plant pathogen interaction; RT-qPCR; soil-borne fungal pathogens

\section{Introduction}

Asparagus officinalis L. is a perennial horticultural crop grown over a wide range of soils and under various climatic conditions. It can remain profitable for about 10 years in temperate regions that have long growing seasons. However, a gradual decline in productivity and the growth of asparagus plants can be observed within the growing period due to the 'asparagus decline' syndrome [1] mainly associated with the elevated soil densities of pathogenic Fusarium spp. [2]. Additionally, 'early decline' and 'asparagus replant disease' can occur when previous asparagus fields are replanted. Fusarium crown and root rot disease affects almost all plant organs. Fusarium oxysporum (SchlтdL.) f.sp. asparagi and Fusarium proliferatum (Matsush.) are considered the main pathogenic species causing asparagus rots worldwide [3-7] and therefore have been studied the most. Depending on the continent and country, there are further Fusarium species involved, such as Fusarium redolens (Wollenw.) and Fusarium solani (Мавт.) in Europe [8]. Here, F. redolens is of interest because this species is closely similar to F. oxysporum [9]. F. oxysporum enters its host through the root and induces either root rots or tracheomycosis when invading the vascular system [10]. Symptoms on asparagus caused by different Fusarium species are similar and include brown lesions on roots, and stems as well as rots of roots, 
rhizomes and stem bases. These damages lead to the stunting of plants, reduced plant size, chlorosis of fern stalks and wilt, and finally, resulting over time in weakening of crowns or loss of crowns $[1,3,4,11]$.

Control of Fusarium disease in commercial fields of asparagus is very complex because of the deep and wide spread root system, the ubiquitous presence of Fusarium in the environment, and its systemic propagation in the host. In addition, the persistence of the Fusarium spp. in plant debris and in soil over many years, due to the formation of resting organs, hampers efforts to control the disease. Thus, fungicidal application is inefficient and affects the environment negatively. Sustained management strategies to minimise Fusarium crown and root rot in asparagus cultivation comprises, on one hand, inoculum reduction and soil environment alterations and, on the other hand, the enhancement of the host defence potentials by developing robust plants [8]. The latter strategy includes three main approaches: breeding of resistant cultivars, strengthening plant health by inducing resistance in plants via biocontrol methods, and stimulation of root health by colonizing asparagus roots with arbuscular mycorrhizae [8]. Approaches for the breeding of Fusarium-resistant cultivars are difficult because of the perennial nature of asparagus, its lack of genetic uniformity (dioecious plants), and the broad genetic diversity of Fusarium in its interaction with the host [2,12-17]. There have been some efforts to manage Fusarium crown and root rot of asparagus by the use of non-pathogenic Fusarium strains or other biological control agents, such as Trichoderma harzianum, to induce systemic acquired resistance, but so far the success in these efforts was moderate $[2,18]$. The stimulation of root health by colonizing asparagus roots with arbuscular mycorrhizae has been more successful against Fusarium attack [2,19-22].

Detailed information about the response of asparagus during the interaction with Fusarium spp. at the molecular and metabolic level are lacking at present. However, such knowledge can support future breeding programmes or the development of plant protection strategies. The occurrence of Fusarium spp. is currently identified using molecular markers and phylogenetic analysis mainly based on sequences of the transcription elongation factor gene TEF-1a [23-25]. In asparagus Fusarium species-specific primers for PCR analysis have been developed [26,27], and the genetic diversity analyses by PCR-denaturing gradient gel electrophoresis [28], and single-stranded conformational polymorphism [29]. Corpas-Hervias et al. demonstrated, via random amplified polymorphic DNA-polymerase chain reaction (RAPD-PCR), the affiliation of F. proliferatum and F. moniliforme, renamed to F. verticillioides, to one group [30]. Amplified fragment-length polymorphism fingerprinting identified F. redolens as a pathogen involved in root, crown and spear rot of asparagus [9]. Nowadays, occurrence of $F$. redolens is also tested using molecular markers [31]. The presence of different Fusarium species isolated from fields with Fusarium crown and root rot history showed considerable variability among the isolates using intersimple-sequence repeat PCR analysis [7].

Root growth is an important indicator for the development and progress of diseases induced by soil-borne pathogens $[32,33]$. The attack or frequency of host infection by pathogens is influenced by root growth traits such as root length, diameter, surface area, and volume. Tomato plants inoculated with F. oxysporum f.sp. lycopersici showed decreased root lengths and reduced root weight, root surface area and root volume [34]. The perennial asparagus builds an extensive root system that comprises thick, long, storage roots clothed with fine, fibrous, absorptive roots that can be exposed to pathogenic soil-borne Fusarium strains [3]. It has already been reported that F. oxysporum f.sp asparagi causes severe foot and root rot, thus significantly reducing root weight [11]. In this regard it is essential to investigate the characteristics of the root system of asparagus after being attacked by Fusarium species at the early stages of plant growth and plant pathogen interaction.

So far, the impact of different Fusarium species on the root system and root characteristics of asparagus remains unclear. In this work, we evaluated the response of asparagus to the Fusarium species F. oxysporum and F. proliferatum, which are known to be ubiquitous in the soil of asparagus-growing areas affected by Fusarium crown and root rot [3], and to F. redolens, as the species is closely similar to F. oxysporum [9]. The selection of two asparagus cultivars was based on their differences in growth and robustness, according to the breeders' assessments, as differences in response to Fusarium infection 
were assumed. Thus, the objectives of this study were to (i) characterise isolates of F. oxysporum, F. proliferatum and F. redolens at physiological, pathogenic and molecular levels; (ii) identify the defence response of two asparagus cultivars to isolates of the three Fusarium species by verifying fungal DNA presence in infected plants and analysing the expression of defence-related genes by RT-qPCR; and (iii) study root and shoot characteristics and identify root morphology characteristics of two asparagus cultivars in response to infection by the three Fusarium species using an automated analysis of root images.

\section{Results}

\subsection{Identification and Physiological Characterisation of Fusarium Spp.}

In order to analyse whether the efficacy in degrading plant-derived carbon sources is correlated with disease severity caused by the Fusarium spp. isolates, we tested their ability to utilise different plant-derived polysaccharides. Fungal growth on complex polysaccharides and cell wall constituents, cellulose and pectin was slower as compared to the other tested substances (Figure 1). No species-specific growth response was found for cellulose as carbon source. However, F. oxysporum isolates showed better growth on pectin as compared to the other Fusarium species. In addition, extracellular enzymatic activities were analysed in plate tests as another factor influencing the usability of these polysaccharides as carbon source for fungal growth. By visualisation on chromogenic medium, no extracellular enzyme activity was detected when Fusarium spp. were cultivated on the two substrates cellulose and pectin. In contrast, extracellular enzymatic activity was detected on plates containing starch, trehalose, and cellobiose in all tested isolates, with the latter substance being degraded most efficiently (Figure S1). Substrate utilisation of trehalose and starch was significantly higher in F. oxysporum isolates as compared to F. proliferatum and F. redolens (Figure 1).
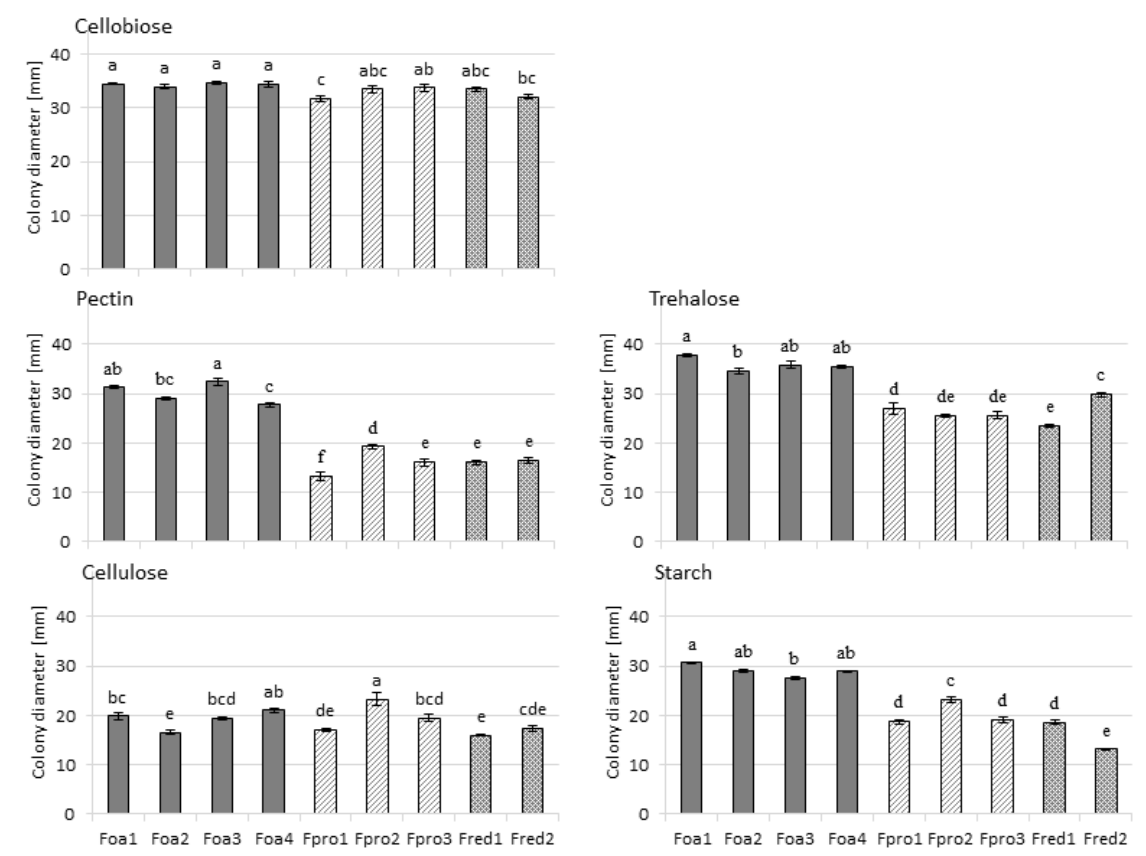

Figure 1. Colony diameter (mm) of Fusarium spp. grown on agar media containing plant-derived polysaccharides as a carbon source. Used Fusarium spp. are F. oxysporum f.sp. asparagi (Foa1, Foa2, Foa3, Foa4), F. proliferatum (Fpro1, Fpro2, Fpro3), and F. redolens (Fred1, Fred2); cell wall components (cellobiose, pectin, cellulose) are shown on the left, storage carbohydrates (starch, trehalose) are shown on the right. Mycelial diameters were measured at four days (cellobiose, trehalose, starch) and seven days (cellulose, pectin) after plate inoculation. The values are the means \pm standard errors $(n=8)$. Significant differences are indicated by different letters ( $p<0.05$; Tukey test). 
To test the potential of matrix-assisted laser desorption ionisation time-of-flight mass spectrometry (MALDI-TOF MS) for the species characterisation of Fusarium isolates, mass spectra on the basis of protein fingerprints of mycelium from overnight fungal cultures were obtained. A comparison of spectra from the different Fusarium spp. by hierarchical clustering showed a clear separation between F. proliferatum isolates and the remaining isolates, while no separation between F. oxysporum and F. redolens isolates was found (Figure 2).

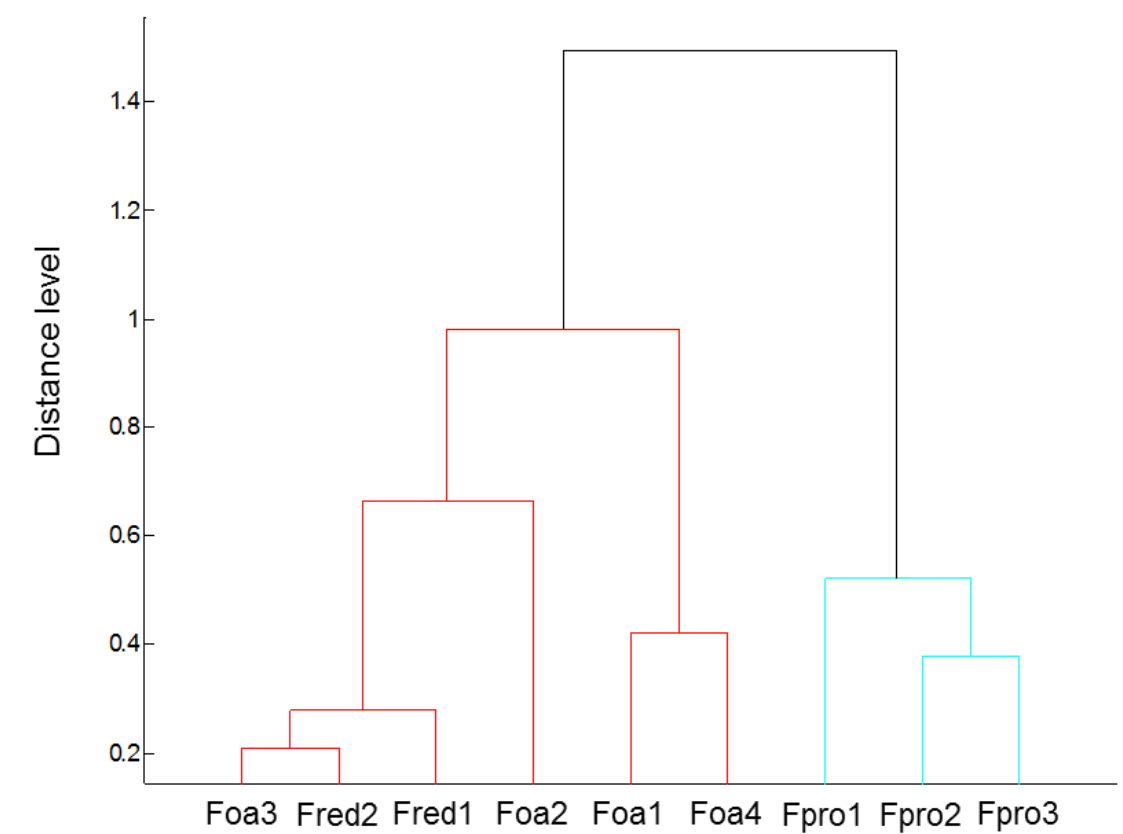

Figure 2. Cluster analysis of matrix-assisted laser desorption ionisation time-of-flight mass spectrometry (MALDI-TOF MS) spectra of F. oxysporum f.sp. asparagi (Foa1, Foa2, Foa3, Foa4), F. proliferatum (Fpro1, Fpro2, Fpro3), and F. redolens (Fred1, Fred2). Distance is displayed in relative units.

\subsection{Aggressiveness of Fusarium spp. Isolates on Asparagus Plants}

Possible differences in the aggressiveness of Fusarium isolates and the susceptibility of the two asparagus cultivars, 'Backlim' and 'Rapsody', were initially tested by monitoring disease symptoms and plant growth. The typical symptoms on roots were brown to reddish-brown necrotic spots and lesions of variable length on both storage and fibrous roots. The tissue within the rhizome was strongly affected so that the inner tissue of storage roots was degraded and roots consisted only of root rhizodermis and the central cylinder. This was predominantly observed by inoculation with F. proliferatum and F. redolens isolates (Figure S2). Control plants did not show any symptoms. Two-way ANOVA of DS of roots showed no interaction between cultivars and isolates. Therefore, the influence of isolates on DS is statistically analysed across both cultivars. However, with regard to the biological difference of 'Backlim' and 'Rapsody' in plant performance, we show the effect of isolates on the DS of roots separately for each cultivar, being aware that statistical significance between isolates and control counts for both cultivars likewise. This type of presentation allows the comparison between treatments differing both in cultivar and isolate level [35]. Disease severity (DS) ratings of roots inoculated with Fusarium spp. isolates differed significantly from the control plants (Figure 3 and Figure S3). DS ratings showed a significant species-specific aggressiveness on the roots of both cultivars: F. redolens was the most aggressive species followed by F. proliferatum and thereafter F. oxysporum. Between the cultivars 'Backlim' and 'Rapsody' no significant difference in susceptibility of roots was observed. DS values were significantly discriminable between inoculation with the isolates of the three Fusarium species on 'Backlim' and 'Rapsody'; except for isolate Fpro3 that had similar impact like Foa1 and Foa4. Among the F. oxysporum f.sp. asparagi isolates Foa1 and Foa4 were likewise aggressive and more 
aggressive than Foa2 and Foa3 but they still did not cause DS scores higher than 2 and fell below the normalised rank mean of 0.5 (Figure 3). No difference in aggressiveness was observed among the F. proliferatum isolates Fpro1 and Fpro2, with both causing higher DS than Fpro3 (Figure 3). The highest DS ratings on both cultivars were caused by the two F. redolens isolates Fred1 and Fred2, which differed significantly from each other. In contrast to root, the DS ratings of ferns were very low, with highest value of 1.9, and almost no differences among the Fusarium spp. (Figure S4). The DS of ferns did not differ significantly between the Fusarium species, and the correlation between the DS of roots and of stems was not significant $\left(\mathrm{r}^{2}=0.347\right)$.

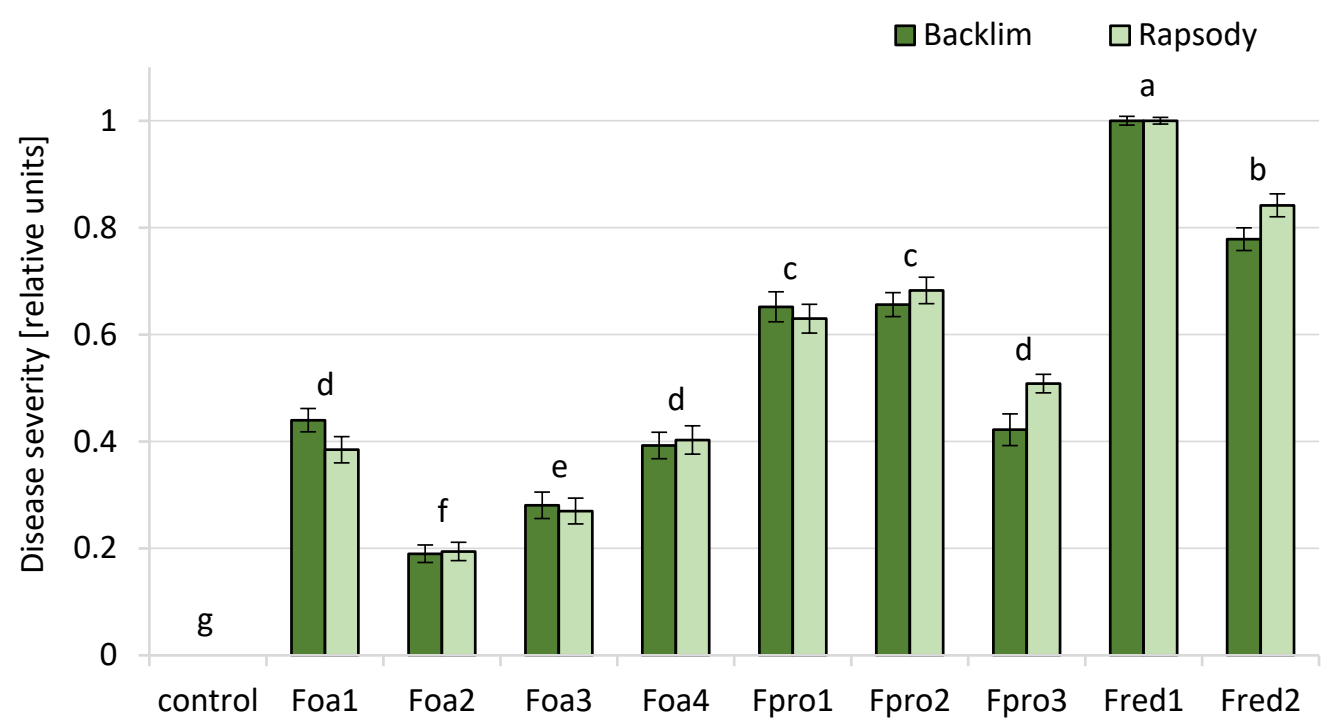

Figure 3. Disease severity (DS) of roots of asparagus 'Backlim' and 'Rapsody'. Plants were inoculated at BBCH 12-13 with isolates of either Fusarium oxysporum f.sp. asparagi (Foa1, Foa2, Foa3, Foa4), F. proliferatum (Fpro1, Fpro2, Fpro3), F. redolens (Fred1, Fred2) with 6-8 $\times 10^{6}$ conidia $\mathrm{mL}^{-1}$, or with water (control) and sampled 8 weeks after inoculation $(n=9)$. The values are the means of 'Backlim' and 'Rapsody' \pm standard errors of normalised ranks. The effect of isolates on plants was statistically analysed over both cultivars likewise; different letters show significance among the Fusarium spp. isolates and control $\left(p<0.0001 ; \chi^{2}\right.$ test).

Two-way ANOVA of root fresh weight (FW) revealed no interaction between cultivars and isolates. We found a significant main effect of cultivar and isolate on root FW accumulation; root FW between the cultivars was significantly different. Thus, mean values of cultivars are depicted separately and statistical significance between isolates and control counts for both cultivars likewise. Root FW after inoculation with all isolates was significantly lower than the control. Among all isolates, Foa2, Foa3, and Foa4 had significantly lowest impact on FW reduction compared to Fpro3, Fred1, and Fred2. The highest impact was observed on plants inoculated with $F$. redolens isolate Fred1 (Figure 4A).

Two-way ANOVA of fern FW revealed no interaction between cultivars and isolates. We found significant main effect of cultivar and isolate on fern FW accumulation; fern FW between the cultivars differed significantly (Figure 4B). Thus, mean values of cultivars are depicted separately and statistical significance between isolates and control counts for both cultivars likewise. Compared to the control, a significant reduction in fern FW was only observed when plants were inoculated with F. proliferatum isolate Fpro3 and F. redolens isolates Fred1 and Fred2 (Figure 4B). A medium but significant correlation was observed between the DS of roots and root FW $\left(\mathrm{r}^{2}=0.539\right)$, and between root DS and fern FW $\left(r^{2}=0.533\right)$. The correlation between the FW of root and fern was highly significant $\left(r^{2}=0.835\right)$. 
(A)

$\square$ Backlim $\square$ Rapsody

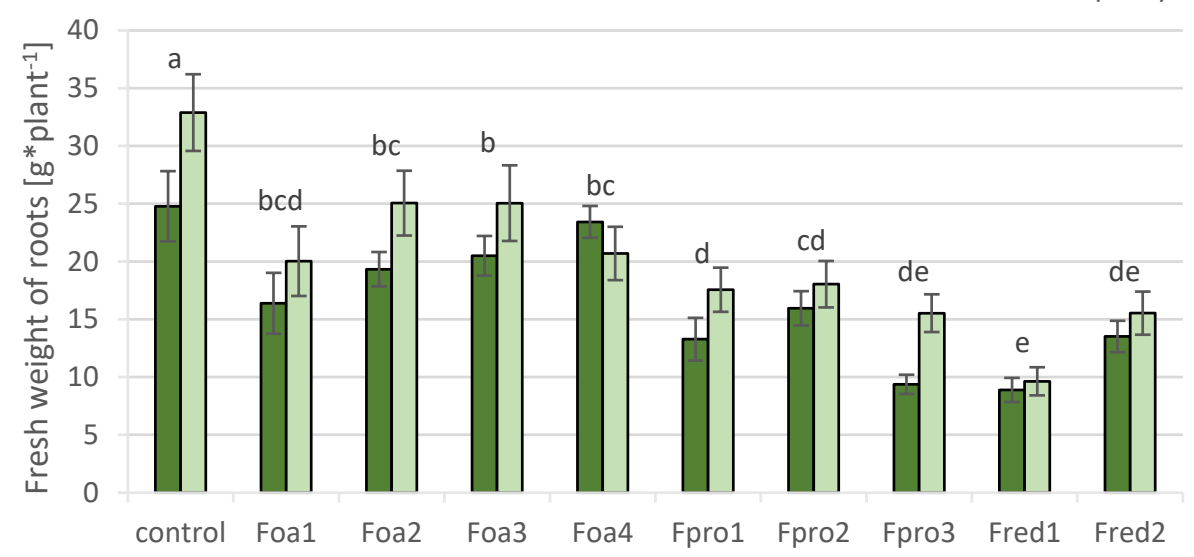

(B)

口Backlim $\square$ Rapsody

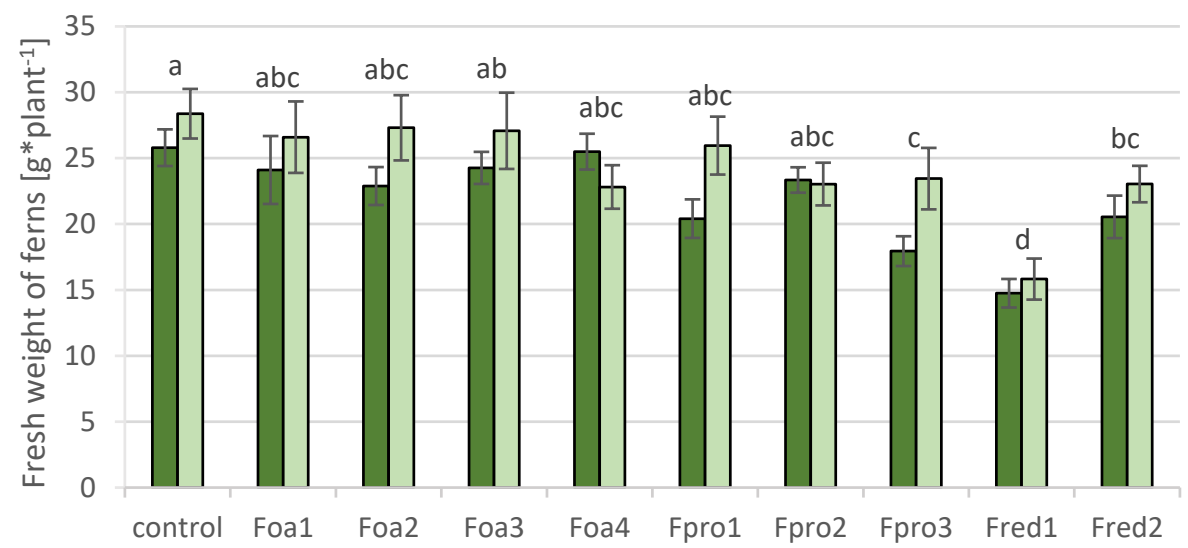

Figure 4. Fresh weights (g) of roots (A) and ferns (B) of asparagus 'Backlim' and 'Rapsody'. Plants were inoculated at BBCH 12-13 with isolates of either Fusarium oxysporum f.sp. asparagi (Foa1, Foa2, Foa3, Foa4), F. proliferatum (Fpro1, Fpro2, Fpro3), F. redolens (Fred1, Fred2) with 6-8 $\times 10^{6}$ conidia mL $^{-1}$, or with water (control) and sampled 8 weeks after inoculation $(\mathrm{n}=9)$. The values are the means of 'Backlim' and 'Rapsody' \pm standard errors. The effect of isolates on the fresh weight of plants was statistically analysed over both cultivars likewise; different letters show significance among the Fusarium spp. isolates and control (Tukey test; $p<0.05$ ).

\subsection{Molecular Detection of Fusarium spp. in Stem Tissue}

The specific detection of Fusarium spp. was carried out in the stem bases of harvested plants to provide evidence of fungal spread in inoculated plants. Species-specific primers were based on sequence variations, previously analysed and standard curves were calculated in the presence of plant DNA as described. Although proof of presence of the specific fungal DNA was clear evidence of infection, the amount of fungal DNA did not necessarily correlate with the severity of disease symptoms. However, a certain relationship between fungal DNA in the stem bases of asparagus and root FW after inoculation with Fusarium spp. was detectable in both cultivars 'Backlim' $\left(\mathrm{r}^{2}=0.402\right)$ and 'Rapsody' $\left(r^{2}=0.690\right)$ (Figure S5). 


\subsection{Expression of Defence-Related Genes}

Quantitative real-time reverse transcription PCR was performed to analyse the RNA accumulation of defence genes coding for pathogenesis-related proteins. Differences in the relative expression levels of pathogenesis-related protein 1 (PR1-2), pathogenesis-related protein 1-like (PR1-4), cationic peroxidase 1-like $(P O X)$, and phenylalanine ammonia-lyase $(P A L)$ in the stem bases of harvested plants are shown in Figure 5. While the steady-state levels of mRNA coding for PAL were unchanged in both cultivars 8 weeks after inoculating roots with Fusarium spp. isolates, a significant reduction in the steady-state levels of mRNA of $P O X$ was detectable in 'Rapsody' after inoculation with F. oxysporum and $F$. redolens isolates. An induction of $P R$-genes was found in both cultivars, with the strongest increase in relative gene expression after inoculation with $F$. redolens. The expression increase of PR1-2 was significant and higher in 'Backlim' than in 'Rapsody'.

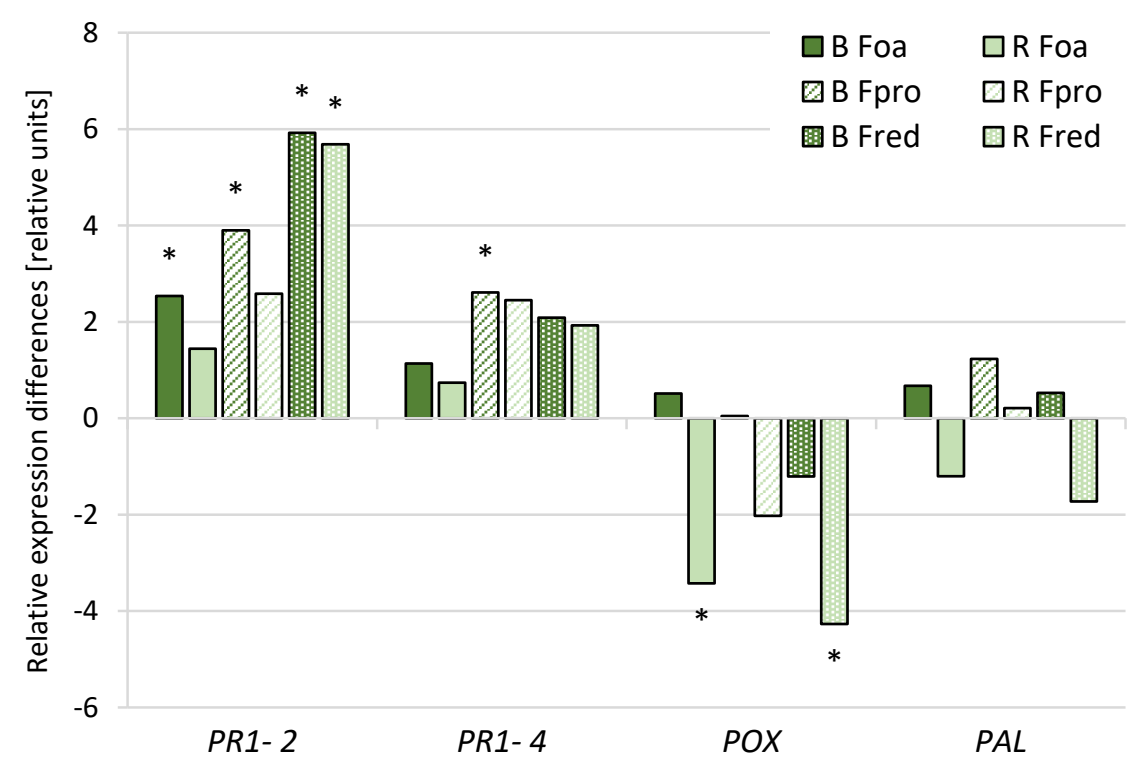

Figure 5. Gene expression analysis in stem bases of asparagus 'Backlim' (B) and 'Rapsody' (R). The plants were inoculated with isolates of Fusarium oxysporum f.sp. asparagi (Foa), F. proliferatum (Fpro), F. redolens (Fred), and water (control) $(\mathrm{n} \geq 6)$. The values are the differences in relative expression levels between the means of treated samples, calculated as $-\Delta \Delta \mathrm{Cq}=\Delta \mathrm{Cq}$ (Fusarium spp. inoculated sample) $-\Delta \mathrm{Cq}$ (respective control sample). * stands for significance between inoculated samples and control samples of the respective cultivar ( $p \leq 0.05 ; t$-test). PR1-2, pathogenesis-related protein 1 (XP_020276576,); PR1-4, pathogenesis-related protein 1-like (XM_020409857,); POX, cationic peroxidase 1-like (XM_020420634); PAL, phenylalanine ammonia-lyase (XM_020404206).

\subsection{Changes in Root Morphology}

Based on the significant disease symptoms in the roots of asparagus plants that were inoculated with Fusarium spp. isolates, a more quantitative investigation of root morphology was performed using image analysis. Two-way ANOVA revealed no interaction between cultivars and isolates. Statistically significant difference between isolates and control counts for 'Backlim' and 'Rapsody' likewise. Because of biological cultivar specification, also, here, the mean values of cultivars are depicted separately. No difference between cultivars was observed by none of the traits except for fibrous root radius. The inoculation of asparagus plants with the nine Fusarium spp. isolates was associated with a decrease in total length of both, fibrous and storage roots, as measured separately (Figure 6). Total root lengths of plants inoculated with F. oxysporum isolate Foa1, F. proliferatum isolates Fpro1 and Fpro3, and F. redolens isolates Fred 1 and Fred2 were significantly lower than control plants (Figure 6). Isolate Fred1, provoking the highest DS among the nine tested Fusarium spp. (Figure 3), caused a storage root 
length reduction of $46 \%$ compared to control plants. A significant reduction of storage root length of 36 and $40 \%$ was also observed when plants were inoculated with Fpro1 and Fpro3 (Figure 6).

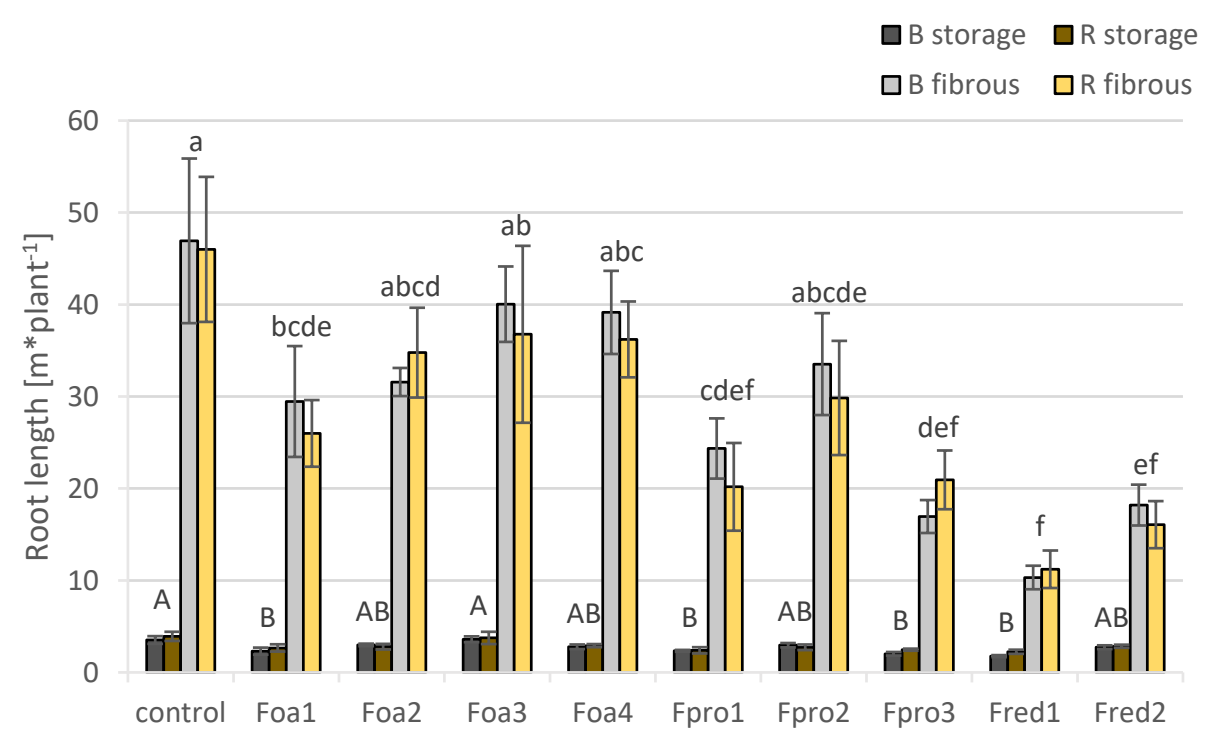

Figure 6. Total length of storage and fibrous roots (m) of asparagus 'Backlim' (B) and 'Rapsody' (R). Storage and fibrous roots were measured separately and summed up to total length $(\mathrm{n}=6)$. Plants were inoculated with isolates of either Fusarium oxysporum f.sp. asparagi (Foa1, Foa2, Foa3, Foa4), F. proliferatum (Fpro1, Fpro2, Fpro3), F. redolens (Fred1, Fred2), or with water (control). The values are the means of 'Backlim' and 'Rapsody' \pm standard errors. The effect of isolates on the total length of storage and fibrous roots was statistically analysed over both cultivars likewise; different letters show significance among the Fusarium spp. isolates and control (Tukey test; $p<0.05$ ).

F. redolens isolate Fred1 significantly reduced the fibrous root lengths of both cultivars and induced a decrease of approximately 77\% (Figure 6). In addition, Fred2 caused a reduction of fibrous loot length by $63 \%$. Among the F. proliferatum isolates Fpro1 and Fpro3 caused significant fibrous root length reductions of ca. 50 and $60 \%$. F. oxysporum isolate Foa1 had a significant effect on plants when compared to controls. DS of roots correlated significantly with fibrous root length $\left(\mathrm{r}^{2}=0.499\right)$, but not with the storage root length $\left(r^{2}=0.406\right)$. High correlation values between root length and fern FW $\left(r^{2}=0.759\right)$, and between root length and root FW $\left(r^{2}=0.890\right)$ show a close relation between these two traits.

No impact of F. oxysporum was observed on the root radius, subdivided into fibrous and storage roots radius (Figure S6). F. proliferatum isolate Fpro3 caused a significant reduction in storage and fibrous roots' radius

As a consequence of decreased root lengths, the fibrous and storage roots' volumes of plants that were inoculated with the Fusarium spp. isolates Foa1, Fpro1, Fpro2, Fpro3, Fred1, and Fred2 were significantly reduced (Figure 7).

The root surface area of 'Backlim' and 'Rapsody' control plants was 850 and $875 \mathrm{~cm}^{2}$, respectively (Figure 8). Inoculation with Fpro1, Fpro3, Fred1 and Fred2 reduced root surface area to nearly half of that of the control plants. The utmost reduction about more than $500 \mathrm{~cm}^{2}$ was caused by inoculation with $F$. redolens isolate Fred1. F. oxysporum f.sp. asparagi isolate Foa1 and Fpro2 also had a significant impact on the surface area reduction of plants (Figure 8). The correlation values between root surface area and root DS, root FW and stem FW $\left(\mathrm{r}^{2}\right.$ root DS $=0.583 ; \mathrm{r}^{2}$ root FW $=0.908 ; \mathrm{r}^{2}$ stem FW $\left.=0.689\right)$ indicate $\mathrm{a}$ tense relation between these traits. 


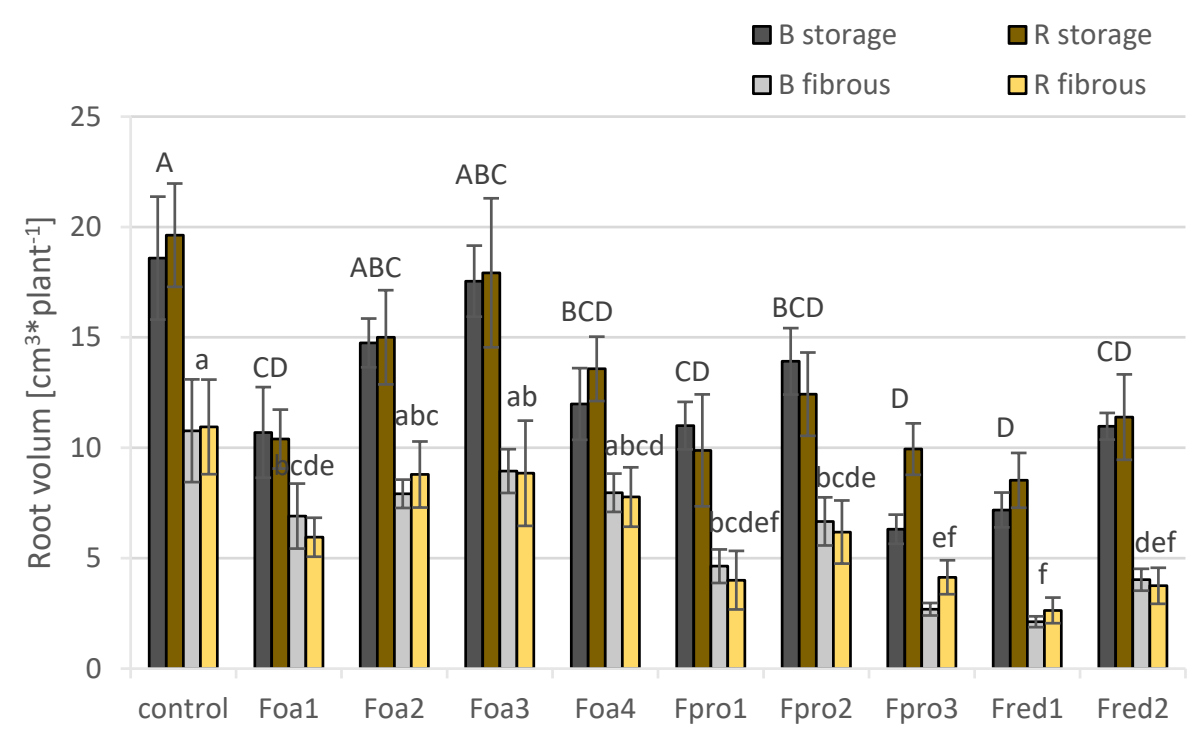

Figure 7. Root volume $\left(\mathrm{cm}^{3}\right)$ of asparagus 'Backlim' (B) and 'Rapsody' (R). Plants were inoculated with isolates of either Fusarium oxysporum f.sp. asparagi (Foa1, Foa2, Foa3, Foa4), F. proliferatum (Fpro1, Fpro2, Fpro3), F. redolens (Fred1, Fred2), or with water (control) $(n=6)$. The values are the means of 'Backlim' and 'Rapsody' \pm standard errors. The effect of isolates on root volume of storage and fibrous roots was statistically analysed over both cultivars likewise; different letters show significance among the Fusarium spp. isolates and control ( $p<0.05$; Tukey test).

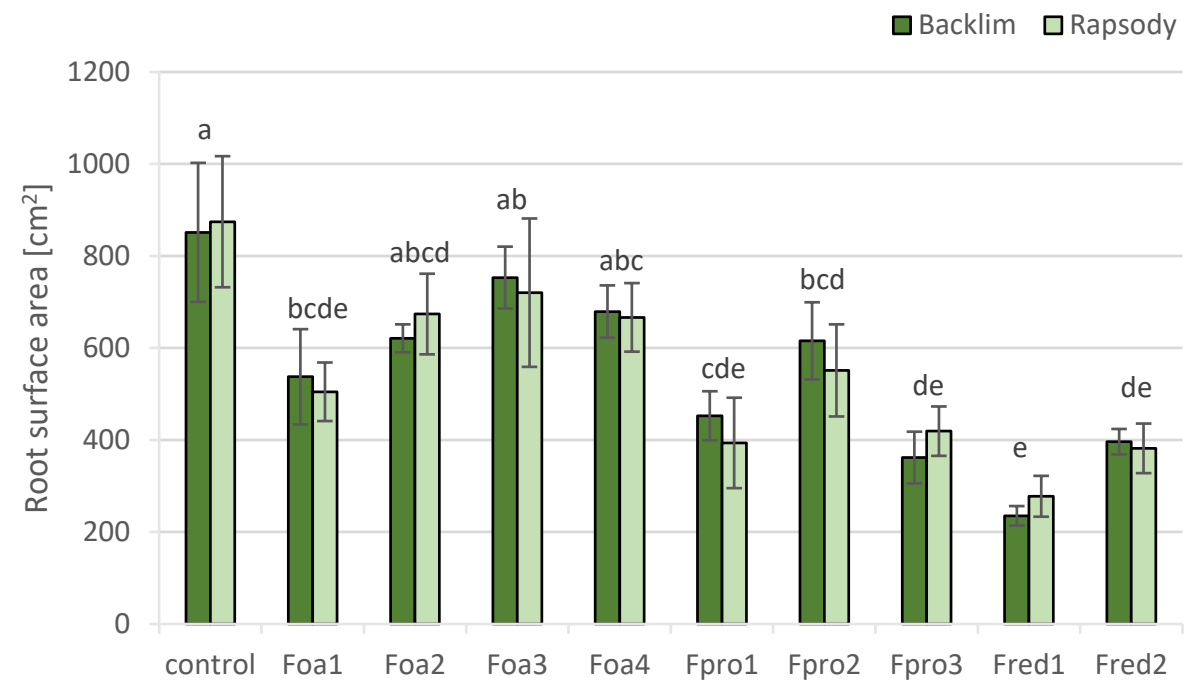

Figure 8. Root surface area $\left(\mathrm{cm}^{2}\right)$ of asparagus 'Backlim' and 'Rapsody'. Plants were inoculated with isolates of either Fusarium oxysporum f.sp. asparagi (Foa1, Foa2, Foa3, Foa4), F. proliferatum (Fpro1, Fpro2, Fpro3), F. redolens (Fred1, Fred2), or with water (control) $(n=6)$. The values are the means of 'Backlim' and 'Rapsody' \pm standard errors. The effect of isolates on root surface area was statistically analysed over both cultivars likewise; different letters show significance among the Fusarium spp. isolates and control ( $p<0.05$; Tukey test).

\section{Discussion}

Asparagus plants can be infected by different Fusarium species and are colonised via the roots. The influence of Fusarium on the root growth characteristics of asparagus depending on the species has not been studied yet. In this study, the impact of four isolates of $F$. oxysporum, three of $F$. proliferatum and two of F. redolens was analysed on the asparagus cultivars 'Backlim' and 'Rapsody', with different 
growing parameters. Hence, we expected differences in response to Fusarium infection depending on the cultivars.

Since different Fusarium spp. can occur on asparagus, the availability of a rapid and safe species-specific diagnosis tool would be useful. Nowadays, the identification of microbial pathogens is routinely performed using matrix-assisted laser desorption ionisation time-of-flight mass spectrometry (MALDI-TOF MS, Bruker Daltonik, Bremen, Germany ), especially for bacterial iso lates [36]. Additionally, mass-spectrometry-based approaches have also been applied successfully for the identification and differentiation of Fusarium species based on spore protein profiles [37,38]. Furthermore, MALDI-TOF MS peptide/protein fingerprints have been used to distinguish closely related species in the Fusarium fujikuroi species complex [39], and for in situ diagnosis in infected plant tissue [40]. Here, we have tested the potential of MALDI-TOF MS to distinguish the used Fusarium species based on protein fingerprints of mycelium. A reliable separation between F. proliferatum and the remaining F. oxysporum and F. redolens isolates was found. A comparable pattern of similarities among these Fusarium spp. was shown by Baayan et al., who performed AFLP fingerprinting followed by hierarchical clustering [9]. With an increasing database of fungal protein fingerprints, the future application of this rapid and economic tool for pathogen diagnosis should lead to the establishment of better and, also, in situ fungal pathogen detection.

The comparative analysis of translated fungal genomes revealed that the highest number of carbohydrate-active enzymes occurs in necrotrophic and hemibiotrophic plant pathogenic fungi, with Fusarium spp. ranking among the highest [41]. The synthesis of cell wall degrading enzymes, a subset of carbohydrate-active enzymes, is of high importance during plant infection with Fusarium spp. [42], as some of those are secreted to facilitate infection and to exploit the plant carbon source. In this study, we intended to answer the question if differences in the activity of carbohydrate-active enzymes between the tested Fusarium spp. are given. It is to assume that a relation between the ability to degrade plant-derived carbon sources and aggressiveness exist. A species-specific substrate utilisation was found for pectin, trehalose and starch, although the response was contrarious to what was found for isolates of F. culmorum $[43,44]$. The least aggressive F. oxysporum isolates showed the highest ability to degrade pectin and to utilise starch and trehalose, indicating that other factors, despite the tested carbohydrate-active enzyme activities account for species-specific aggressiveness to asparagus.

The impact of F. oxysporum, F. proliferatum and F. redolens isolates was investigated at an early growth stage of asparagus with particular emphasis on changes in the root morphology. Based on the present pathogenicity test, we found that our tested isolates differed significantly in their aggressiveness, and, to a certain extent, a classification of the Fusarium spp. in four pathogenicity groups was possible. F. redolens isolates were the most aggressive strains followed by the moderate aggressive $F$. proliferatum and the weakly aggressive $F$. oxysporum isolates. Based on the severity of disease symptoms, significant differences in aggressiveness were observed between the isolates of each species. Following this classification, the F. proliferatum isolate Fpro3 should rather be ranged in the group of the two pathogenic F. oxysporum isolates Foa1 and Foa4. Following the argumentation of Elmer and Stephens [45] who considered isolates causing DS higher than $20 \%$ as pathogenic on asparagus, the two isolates Foa 2 and Foa3 that were not able to cause DS scores higher than 1 (that includes a diseased root area up to $20 \%$ ) could be rated as non-pathogenic. However, it has to be noted that our testing was performed with rather young plants and long-term observations in fields may reveal stronger and increasing impact over time. It is worth mentioning that, in the past, many pathogenicity tests with Fusarium strains performed in different countries resulted in diverse outcomes. Borrego-Benjumea et al. [7] showed in their pathogenicity tests that F. oxysporum, F. solani and F. acuminatum were highly aggressive, whereas F. proliferatum and F. redolens were weakly aggressive. The most aggressive Fusarium spp. in Spain were F. proliferatum and F. solani [30], and, in the Netherlands, Blok and Bollen [11] found, in F. oxysporum isolates, the highest aggressiveness. In Japan and the United Kingdom, F. oxysporum and F. proliferatum were the most pathogenic Fusarium spp. responsible for asparagus decline $[29,46]$. In summary, this 
demonstrates that the assessment of pathogenicity depends on the analysed isolates, the cultivars, and the interaction of both with the environmental conditions.

The results in the present experiments show a comparable level of susceptibility in the two cultivars, while they were chosen because of differences in growth and robustness. There was no cultivar-specific significant difference in the DS of roots caused by the various Fusarium spp. Thus, both cultivars can likely be regarded as equally susceptible to at least the tested Fusarium spp. isolates.

The aggressiveness of the isolates of the three Fusarium species is largely reflected in the root traits. Compared to control plants, the root FWs of plants were reduced when they were inoculated with each isolate. A decrease in root FW was noticed with increasing DS of roots. These results are in accordance with the findings of Corpas-Hervias et al. [30], who found a general trend in the decrease in root dry weight with increasing severity of root rot symptoms. An impact of the isolates on fern FW was obvious when plants were inoculated with F. proliferatum isolate Fpro3 and F. redolens isolates Fred1 and Fred2, with Fred1 being the most aggressive isolate. The impact of the F. oxysporum f.sp. asparagi isolates was low, highlighting the weak aggressiveness of this Fusarium species, but also Fpro1 and Fpro2 had only weak impact on the FW of fern.

In our experiments, the DS of ferns was very low and we observed no significant impact of the fern DS on root FW $\left(r^{2}=0.198\right)$ or on fern FW $\left(r^{2}=0.347\right)$, and also no significant correlation existed between the DS of roots and DS of ferns $\left(r^{2}=0.347\right)$. This is in contrast to the results of Corpas-Hervias et al. [30], who found a highly significant correlation between root rot and fern severity ratings. It is assumed that the rather short duration of our experiment with plant harvest eight weeks post inoculation may have minimised the impact of the pathogens on fern FWs, although the DNA of the pathogen was already detectable in the stem bases. The presence of fungal DNA clearly provides proof of plant infection; however, the amount of fungal DNA measured in the respective tissue does not necessarily correlate with DS. Since we have inoculated plant roots, the detection of fungal DNA in stem bases is an expression of fungal spread into aerial parts of the plant. This is the typical strategy of soil-borne fungal pathogens that cause vascular wilt in host plants. After expansion in the host they produce resting structures in plant tissues that get incorporated into soil; from there they again start interaction by first challenging the roots and subsequently spread inside the vascular tissue [47]. In addition, the first evidence of the ferns' response to the presence of the pathogen was detected using gene expression analysis. The expression of $P R 1$ was significantly higher and the expression of another pathogenesis-related gene (PR9) $P O X$ was unchanged or even reduced in stem bases, thus resembling a typical $P R$-gene expression profile upon Fusarium infection [48]. The expression of a key biosynthetic enzyme, mainly involved in defence mechanisms, that catalyses the first step in the synthesis of a variety of polyphenol compounds $P A L$ [49] remained unchanged. This is in contrast to other experiments, where the presence of F. oxysporum f.sp. lycopersici strains induced PAL expression as a clear evidence of induced systemic acquired resistance in tomato [50]. Symptoms on ferns and the reduction of fern FW seems to be the result of a longer period of interaction between plant and the soil-borne Fusarium spp., and it would be interesting to analyse the impact of the pathogens on aboveground parts of plants at this later stage of pathogenesis.

The morphology of inoculated asparagus roots classified in storage and fibrous roots was measured by means of a new automated processing pipeline. No significant difference between 'Rapsody' and 'Backlim' was observed regarding these traits, except for fibrous roots radius. A general tendency in the decrease in root length could be observed with increasing severity of root symptoms. The measured root volume values showed a general tendency like the results of the total root length, and no clear conclusion could be drawn regarding data of radius of fibrous and storage roots. We assume that most probably after attack with the pathogen, particularly fibrous roots die off and hence the remaining roots that were measured were almost not injured and stayed unaffected by the pathogen. Additionally, symptoms caused by Fusarium spp. on affected roots comprised lesions that were not yet so severe on root tissue at assessment time and therefore root radius was less influenced. The decrease in total root length resulted in a reduction of root surface area. Apart from F. proliferatum 
isolates Fpro1, Fpro2, and Fpro3, and both F. redolens isolates Fred1, and Fred2 also F. oxysporum f.sp. asparagi isolate Foa1 caused a clear reduction in the root surface area. Altogether, it can be concluded that the two F. redolens isolates had the highest impact followed by F. proliferatum isolates Fpro1 and Fpro3. F. oxysporum f.sp. asparagi isolates had the lowest effect on root traits and fresh weight. Thus, the variation in aggressiveness of the isolates was to some degree reflected in the effect of the isolates on fresh weight and root morphology.

These observations on root morphology are in accordance with other studies with Fusarium spp. and further soil-borne pathogens. For example, a decrease in root length, root weight, root surface area, and root volume was observed on tomato plants inoculated with F. oxysporum f.sp. lycopersici [34]. Crosby [51] stated that total root length, fine and small root length, and the number of root tips were greater for a melon cultivar that was tolerant to the soil-borne fungus Monosporascus cannonballus. On the other hand, there are also opposed statements on the correlation between root traits and the impact of soil-borne pathogens. For example, Cichy et al. [52] could not find significant interactions between attacks with F. solani f.sp. phaseoli and the root system traits of beans. They made the short experiment duration of 32 days responsible for the missing impact of the pathogen on the host. In a soil compaction-F. solani root rot interaction study with large- and medium-rooted pea lines, Kraft and Boge [53] asserted that larger-rooted pea lines had significantly more roots than did the smaller-rooted line. However, they observed that reduction in root growth was stronger for the larger-rooted lines than for the smaller-rooted pea line.

Insights into the root morphology of plants are fundamental for the comprehension of root functionality. Fibrous roots of asparagus are mainly responsible for water and nutrient uptake and the storage roots have the role as storage locations for reserve carbohydrates (mostly fructans). The considerable decreases in fresh weight, root length, root volume, and root surface area as shown in this study entail the limitation of water and nutrient uptake of diseased plants and result in weakness and stunted growth of plants. The ability of asparagus plants to store carbohydrates in these roots is limited when storage roots are reduced and this has a negative effect on the production of spears for the growing season and hence on yield. In this study, we could clearly differentiate the aggressiveness of Fusarium spp. isolates. Moreover, the measured root traits, including root fresh weight, total root length, root volume, and root surface area, turned out to be meaningful indicators for the general status of the plant. The correlations between the severity of root rot symptoms and root traits were mostly significant. Arias et al. [54] observed for some Fusarium spp. isolates significant linear relationships between soybean yield and root symptoms and concluded from their studies that the root morphological characteristics of soybean were more consistent indicators of yield loss than root rot severity caused by Fusarium spp. on soybean. The yield loss in asparagus that is related with the asparagus decline is also related to the presence of Fusarium spp. in soil, but following Elmer [55] apart from this soil-borne pathogen there are many other indicators that contribute to asparagus decline. Guo [56] specified that asparagus cultivars with high yield potential exhibit a big root-stem-ratio and underlined the relevance of root mass for yield. To promote vigorous root systems, proper balance of the nutrient elements $\mathrm{N}, \mathrm{P}$, and $\mathrm{K}$ is essential particularly to help plants to withstand biotic and abiotic stress. By means of management practices to overcome poor nutrition, abiotic stressors for the implication of asparagus decline, such as water insufficiency and malnutrition, can be resolved [55]. In this short-time experiment, we could not prove the consequences of limited water and nutrient uptake, but we show that the root system is heavily restricted when roots are attacked by the pathogenic Fusarium spp. and poor nutrition can also be initiated by diseased root systems that are restricted in water and nutrient uptake. This is why the prevention of lesions and injuries of the root system of asparagus is a main concern.

Most Fusarium species synthesise toxic secondary metabolites, known as mycotoxins, that are defined as evoking a toxic response when introduced in low concentrations to animals. It was shown for isolates of $F$. proliferatum from asparagus spears origin to produce moniliformin and fumonisin B1, and F. oxysporum to produce only moniliformin $[57,58]$. Moreover, the respective toxins can be found in basal parts of asparagus spears that were infected with the respective Fusarium species [59,60]. However, 
environmental factors affecting mycotoxin biosynthesis in the fungus and the roles of such mycotoxins in the infected plants are not yet fully understood [61,62]. The species-specific biosynthesis of such mycotoxins in the Fusarium asparagus interaction and its impact on root and shoot characteristics of asparagus plants should be the topic of a targeted future analysis.

\section{Materials and Methods}

\subsection{Fusarium spp. Cultivation}

The Fusarium spp. isolates used in this study are listed in Table 1. The isolates were provided either on synthetic nutrient-poor agar [52] or on potato-dextrose agar (PDA; Potato Dextrose Agar, Carl Roth $\mathrm{GmbH}$, Karlsruhe, Germany) plates. Single-spore isolates were made of each isolate and cultivated on PDA in the dark at $25^{\circ} \mathrm{C}$ for 10 days for the studies.

Table 1. Overview of Fusarium. oxysporum f.sp. asparagi, F. proliferatum and F. redolens isolates from asparagus from different German regions used for pathogenicity test, and molecular and physiological assays.

\begin{tabular}{|c|c|c|c|c|c|}
\hline Isolate & Origin Code & Species & Origin & Isolation & Source * \\
\hline Foa1 & Ob2-66 & F. oxysporum & Brandenburg & 2002 & HUB \\
\hline Foa2 & $10 \mathrm{~K} 3.3$ & F. oxysporum & Niedersachsen & 2001 & HUB \\
\hline Foa3 & $45 \mathrm{~K} / 2.1$ & F. oxysporum & Niedersachsen & 2001 & HUB \\
\hline Foa4 & III/3.1 & F. oxysporum & Sachsen-Anhalt & 2011 & JKI \\
\hline Fpro1 & $193-S$ & F. proliferatum & Brandenburg & 2002 & HUB \\
\hline Fpro2 & $219-S$ & F. proliferatum & Rheinland-Pfalz & 2000 & HUB \\
\hline Fpro3 & $88-17 / 1$ & F. proliferatum & Niedersachsen & 2015 & UAS \\
\hline Fred1 & $89-17 / 2$ & F. redolens & Niedersachsen & 2015 & UAS \\
\hline Fred2 & $90-7 / 1$ & F. redolens & Niedersachsen & 2015 & UAS \\
\hline
\end{tabular}

${ }^{*}$ HUB, Humboldt University of Berlin; JKI, Julius Kühn Institute Quedlinburg; UAS, University of Applied Sciences Osnabrück.

\subsection{Fungal Degradation of Polysaccharides and Production of Extracellular Hydrolytic Enzymes}

The Fusarium spp. isolates were tested for their growth on plant-derived polysaccharides by growing them on cellobiose (Fluka Honeywell Specialty Chemicals, Seelze, Germany), trehalose (Carl Roth $\mathrm{GmbH}$ ), Avicel ( $50 \mu \mathrm{m}$ size cellulose, Sigma-Aldrich, Darmstadt, Germany), pectin (Sigma-Aldrich), or starch (neoLab, Heidelberg, Germany). The media contained $0.5 \%$ of respective polysaccharides, $0.1 \%$ yeast nitrogen base (Carl Roth $\mathrm{GmbH}), 0.05 \%$ congo red (Carl Roth $\mathrm{GmbH}$ ) and $1.5 \%$ agar (VWR, Darmstadt, Germany). The plates $(\varnothing 9 \mathrm{~cm})$ were inoculated by placing, at the centre of the plate, an agar plug that was taken from the rim of 10-day-old actively growing colonies of each isolate on PDA (Table 1). Isolates were incubated at $25^{\circ} \mathrm{C}$ for 4 (cellobiose, trehalose, and starch) or 7 days (cellulose, pectin) on the respective agar media. Seven days of incubation on cellulose and pectin was chosen because of the slower growth of these media. The mycelial diameter was measured as an indicator for carbon utilisation, as well as the diameter of congo red discoloration as an indicator of the production of extracellular enzymes. Eight replicate plates were tested per isolate and per carbon source.

\subsection{Species-Discrimination by MALDI-TOF Mass Spectrometry}

Overnight cultures of Fusarium spp. isolates (Table 1), grown in potato-dextrose broth at room temperature under shaking conditions, were pelleted by centrifugation. Proteins contained in the mycelia were extracted using formic acid-based method [63]. A total of $1 \mu \mathrm{L}$ of protein extract was spotted onto a polished steel target (Bruker Daltonik, Bremen, Germany) and air-dried before the addition of a saturated $\alpha$-cyano-4-hydroxycinnamic acid solution as matrix. The MALDI method was calibrated using a bacterial test standard (Bruker Daltonik). 
An ultrafleXtreme MALDI-TOF mass spectrometer (Bruker Daltonik), working in linear positive mode, was used for acquiring mass spectra in the range of $m / z 200-20,000$. Measurements were performed by flexControl v3.4 software (Bruker Daltonik). The MALDI Biotyper v3.1 software (Bruker Daltonik) was used to process the raw spectra, perform a database search against the Bruker Filamentous Fungi Library v1.0 (364 entries) for isolate identification, and to generate a hierarchical clustering of $m / z$ values. Species-discrimination was performed three times with independently grown fungal cultures.

\subsection{Plant Cultivation}

Seeds of Asparagus officinalis L. 'Backlim' (Limgroup B.V., AE Horst, the Netherlands) and 'Rapsody' (Südwestdeutsche Saatzucht GmbH \& Co. KG, Rastatt, Germany) were surface sterilised in water at $55^{\circ} \mathrm{C}$ for $20 \mathrm{~min}$. Then, they were sown in trays filled with substrate consisting of a 1:2 mixture of sterilised sand and standardised plant growth substrate of a volcanic clay and peat soil mixture (Fruhstorfer Erde type P; Havita, Vechta, Germany), and cultivated in a growth chamber at $23^{\circ} \mathrm{C}$ with a 12-h photoperiod until plants had reached a $\mathrm{BBCH}$ growth stage between 12 and 13, describing the evolvement of the second or third stem [64]. Plants were cultivated in a growth chamber at $23 / 18^{\circ} \mathrm{C}$ and $75 / 85 \%$ relative humidity in a day/night cycle with a $16 / 8 \mathrm{~h}$ photoperiod $\left(400 \mu \mathrm{mol} \mathrm{m} \mathrm{m}^{-2} \mathrm{~s}^{-1}\right)$. Plants were watered as required and after cladode development they were fertilised once a week with macro- and micro-nutrients $\left(\mathrm{Ca}\left(\mathrm{NO}_{3}\right)_{2}\left(4.18 \mathrm{~g} \mathrm{~L}^{-1}\right) ; \mathrm{KNO}_{3}\left(1.03 \mathrm{~g} \mathrm{~L}^{-1}\right) ; \mathrm{KH}_{2} \mathrm{PO}_{4}\left(0.35 \mathrm{~g} \mathrm{~L}^{-1}\right) ; \mathrm{K}_{2} \mathrm{SO}_{4}\right.$ $\left(0.43 \mathrm{~g} \mathrm{~L}^{-1}\right) ; \mathrm{Mg}\left(\mathrm{NO}_{3}\right)_{2}\left(0.51 \mathrm{~g} \mathrm{~L}^{-1}\right) ; \mathrm{MgSO}_{4}\left(0.63 \mathrm{~g} \mathrm{~L}^{-1}\right)$, Fe chelate $\left.\left(0.5 \mathrm{~g} \mathrm{~L}^{-1}\right)\right)$.

\subsection{Plant Inoculation and Pathogenicity Testing of Fusarium Spp. Isolates on Asparagus Plants}

Asparagus plants ('Backlim' and 'Rapsody') were carefully removed from the substrate. Roots were rinsed with tap water and prepared for inoculation with spore suspensions. The spore suspension of each isolate (Table 1) was made by flooding single-spore isolate cultures on PDA plates with sterile distilled water and filtering it through four layers of sterile cheesecloth. The number of conidia was microscopically counted (Zeiss Axioskop 2, Carl Zeiss Microscopy GmbH, Jena, Germany) using a haemocytometer and adjusted to $6-8 \times 10^{6}$ conidia $\mathrm{mL}^{-1}$ by dilution with sterile distilled water. Plant inoculation was performed by dipping roots for $30 \mathrm{~min}$ in $10 \mathrm{~mL}$ of the spore suspension of the respective Fusarium isolate and adding $9 \mathrm{~mL}$ of the spore solution around the stem after the plants were transplanted singly in pots $(10 \times 10 \times 11 \mathrm{~cm}, 0.69 \mathrm{~L})$ containing sterile substrate (sand:Fruhstorfer Erde type P 1:1 (vol/vol)). The control plants were inoculated in the same manner but with sterile distilled water. After inoculation, plants were grown in growth chambers as described above until disease assessment. The experiment was performed three times. Each experiment included three replications for each isolate and cultivar. One replicate comprised six plants of the respective cultivar. Pots were placed in a randomised complete block design. Eight weeks after inoculation, Fusarium symptoms were assessed on roots and stems. Roots were removed from pots and thoroughly rinsed in tap water. Disease severity (DS) was rated based on the percentage of affected stems and root system on a $1-5$ scale, where $1=1$ to $20 \%, 2=21$ to $40 \%, 3=41$ to $60 \%, 4=61$ to $80 \%$ and $5=81$ to $100 \%$ of stems showing chlorosis, necrosis or wilt (wilted stems were counted as DS 5) and of roots showing lesions [30]. The means and standard error of DS of stems and roots were calculated over the 9 replicates in total, i.e., from the three performed experiments each including three replications for each isolate and cultivar. After disease assessment, the plants were cut directly above the hypocotyl for fresh and dry weight estimation. Stems and roots were dried at $80^{\circ} \mathrm{C}$ for $48 \mathrm{~h}$. The means and standard error of fresh and dry weight were calculated over the nine replicates of each treatment and cultivar.

In addition to the molecular detection of Fusarium spp. in plant tissue, one plant out of each replicate was used for the re-isolation of Fusarium spp. isolates on plates to fulfil Koch's postulate. Root pieces $(2-3 \mathrm{~cm})$ were washed twice with tap water and dipped for $2 \mathrm{~min}$ in ethanol $(2 \mathrm{~mL}, 70 \%)$ and thereafter dipped for $8 \mathrm{~min}$ in $\mathrm{NaOCl}(1 \mathrm{~mL}, 5 \%+$ Tween20) and finally rinsed with sterile water. The treated root pieces were then placed on PDA amended with streptomycin sulphate $\left(50 \mathrm{mg} \mathrm{L}^{-1}\right)$, 
penicillin-G-potassium $\left(100 \mathrm{mg} \mathrm{L}^{-1}\right)$ and tetracycline hydrochloride $\left(10 \mathrm{mg} \mathrm{L}^{-1}\right)$ and incubated at $25^{\circ} \mathrm{C}$ for 2 days in the dark. Fusarium was determined by a visual and microscopic analysis of conidia [65].

\subsection{Molecular Detection of Fusarium Spp. Isolates in Plant Tissue}

A 1-cm piece of each stem was cut directly at the stem basis of each plant for pathogen DNA detection and gene expression analysis. Samples per plant were immediately frozen in liquid nitrogen and stored at $-80^{\circ} \mathrm{C}$. Samples were taken from five plants per replicate of each treatment. Plant material was ground in liquid nitrogen in an orbital ball mill for 2 min at a frequency of $30 \mathrm{~Hz} \mathrm{~s}^{-1}$ (MM400 Retsch GmbH, Haan, Germany) with three balls of stainless steel with a 5-mm diameter.

Total DNA was extracted from 50 mg ground tissue using the DNeasy Plant Mini Kit (Qiagen $\mathrm{GmbH}$, Hilden, Germany). DNA was quantified spectrophotometrically at $260 \mathrm{~nm}$ (Infinite M200PRO, Tecan Trading AG, Männedorf, Switzerland) using the NanoQuant plate, and quality was checked using absorption at 260 and $280 \mathrm{~nm}$ with a ratio $>1.8$ as acceptable. For the fungal DNA standard curves, mycelium was harvested from single-spore isolates grown for 5 days in liquid culture in PD medium in the dark at $25{ }^{\circ} \mathrm{C}$. DNA from selected isolates per Fusarium spp. were extracted from $50 \mathrm{mg}$ mycelium using the same methods. The standard curves were prepared using serial diluted samples of 2.5-0.001 ng of fungal DNA with and without $20 \mathrm{ng}$ of pure Asparagus officinalis genomic DNA, thus resembling the plant background. Standard curves of $\mathrm{y}=26.66-1.773 \mathrm{x}$ for F. oxysporum f.sp. asparagi, $\mathrm{y}=26.16-1.758 \mathrm{x}$ for $F$. proliferatum and $\mathrm{y}=26.34-1.770 \mathrm{x}$ for $F$. redolens were calculated in the presence of $20 \mathrm{ng}$ of asparagus DNA. For qPCR detection of DNA, the primer concentrations of $200 \mathrm{nM}$ and $3 \mu \mathrm{l}$ of extracted DNA solution were used for each reaction in $10 \mu \mathrm{l}$ with the Sensi Fast SYBR NO ROX Kit (Bioline GmbH, Luckenwalde, Germany). The qPCR cycling was carried out using cycle parameters of $95^{\circ} \mathrm{C}$ for $5 \mathrm{~min}$ to activate the polymerase, followed by 40 amplification cycles of $95^{\circ} \mathrm{C}$ for $15 \mathrm{~s}$ and $60^{\circ} \mathrm{C}$ for $1 \mathrm{~min}$ with signal thresholds set automatically. Primers were based on sequence variations previously analysed by $[7,26,27]$. F. oxysporum f.sp. asparagi, Fo-RT-CL1f1: TTCATTTCTGCTGCTGAGCTTC, FoCL1r: GTCAGTAACTGGACGTTGGTACT; F. proliferatum, FpCL1f: CATGCATCAGACCACTCAAATC, Fp-RT-CL1r1: CGTTTAGCTCATGTTTTCGCTTC; F. redolens, FrEF1f: ATTTTCCCTTCGACTCGCCG, Fr-RT-EF1r2: GATCCGCGCTCATTGTGATTG.

\subsection{Gene Expression Analysis in Stem Tissue Using RT-qPCR}

RNA was extracted from $100 \mathrm{mg}$ of ground tissue using the Qiagen RNeasy Plant Mini Kit including on-column DNaseI digestion (Qiagen, Valencia, CA, USA). RNA was quantified spectrophotometrically at $260 \mathrm{~nm}$ (Nanodrop ND1000, ThermoFisher Scientific, Schwerte, Germany) and quality controlled using a 2100 Bioanalyzer and RNA 6000 Nano kit (Agilent Technologies, Santa Clara, CA, USA) with a determining RNA integrity number (RIN). Single-stranded cDNA synthesis was carried out with $1 \mu \mathrm{g}$ of total RNA using an iScript cDNA Synthesis Kit (Bio-Rad Laboratories GmbH, Feldkirchen, Germany) in a 25- $\mu$ l reaction following manufacturer's instructions, and subsequently diluted 10-fold. RT-qPCR was performed using 96-well reaction plates on a Thermal Cycler CFX96 C1000 Touch (Bio-Rad Laboratories $\mathrm{GmbH}$ ) with the following thermal profile: $95{ }^{\circ} \mathrm{C}$ for $5 \mathrm{~min}, 40$ cycles of $95^{\circ} \mathrm{C}$ for $15 \mathrm{~s}$ and $60^{\circ} \mathrm{C}$ for $1 \mathrm{~min}$, followed by dsDNA melting curve analysis to ensure amplicon specificity. Each reaction was done in a $10-\mu \mathrm{L}$ volume containing $200 \mathrm{nM}$ of each primer, $3 \mu \mathrm{L}$ of cDNA (1:10) and $5 \mu \mathrm{L}$ of Sensi Fast SYBR NO ROX Kit (Bioline GmbH, Luckenwalde, Germany). The data were collected and compiled using CFX Manager Software 3.0 (Bio-Rad Laboratories $\mathrm{GmbH})$. Satisfactory PCR amplification efficiency for each primer pair close to 2 was additionally verified using LinReg software [66]. Relative transcript levels were normalised on the basis of the expression of the invariant control elongation factor 1-alpha (XM_020411981), calculating $\Delta \mathrm{Cq}$ as the difference between control and target products $\left(\Delta \mathrm{Cq}=\mathrm{Cq}_{\text {gene }}-\mathrm{Cq}_{E F 1}\right)$. Reference gene stability was calculated with the CFX Manager software 3.0 (Bio-Rad Laboratories $\mathrm{GmbH}$ ) and also checked with qbase (Biogazelle, Gent, Belgium). At least three biological replicates of each cultivar inoculated with the respective Fusarium isolate were measured in duplicates, and non-template controls were 
included. For comprehensive presentation, the values of the respective species were presented together. Differences in relative expression levels between the treated samples were calculated as $-\Delta \Delta \mathrm{Cq}=\Delta \mathrm{Cq}$ (Fusarium spp. inoculated sample) $-\Delta \mathrm{Cq}$ (mock inoculated sample). The oligonucleotide primer sets used for RT-qPCR are as follows: elongation factor 1-alpha (XM_020411981, EF1), Ao-RT-EF1alfa2f: TTGATAGGCGATCGGGTAAG, Ao-RT-EF1alfa2r: CTCATGTCCCTCACAGCAAA; pathogenesis-related protein 1 (XP_020276576, PR1-2), Ao-RT-PR1f2: TGTTCGAATCTGCCACTACT, Ao-RT-PR1r: TGCCTTCATGTGGTTGGTTA; pathogenesis-related protein 1-like (XM_020409857, PR1-4), Ao-RT-PR1f4: AGGCTTTTGTGATGGATTGG, Ao-RT-PR1r4: CTAGGCGCTCCTTGACGTAG; cationic peroxidase 1-like (XM_020420634, POX), Ao-RT-POX2f1: GCTTCAGCCCAGTTATCGTC, Ao-RT-POX2r1: CATTGACGAAGCAATCATGG; phenylalanine ammonia-lyase (XM_020404206, PAL), Ao-RT-PALf: GTAAACGACAACCCGCTCAT, Ao-RT-PALr: AGCTCCGATACCTGAGCAAA.

\subsection{Analysis of the Root Morphology}

The root systems of two randomly chosen plants of each replicate and cultivar of two experiments were used for imaging analysis. The data of the two experiments were pooled. To avoid overlapping, the washed roots were carefully separated on top of a DIN A4 sized bright frame and were imaged with a stage mounted digital camera (Canon EOS60 + EF 17-40 mm). Approximately 5 RAW images were obtained from each root tray with the following settings: aperture 10, ISO setting: 100 and focal length: $38 \mathrm{~mm}$. The effective image resolution was about 450 DPI. A processing pipeline was realised by a MATLAB script (MATLAB. (2017) version 9.3 (R2017b). The MathWorks Inc., Natick, MA, USA) that provided cleaned and margin-free binary root images to IJ-Rhizo (Rasband, W.S., ImageJ, U.S. National Institutes of Health, Bethesda, MD, USA, https://imagej.nih.gov/ij/, 1997-2018) [67] and performs additional pre- and post-processing steps. IJ-Rhizo was used to measure the root length of different diameter classes.

This automated processing pipeline consisted of the following steps: keyboard macrobased RAW-file conversion (Digital Photo Professional, 2011), median filtering over a tif-converted raw image file stack ( $n \sim 5$ images), margin detection and removal via hough transform, root segmentation and dirt detection and removal. Root segmentation and dirt detection was based on fitted Gaussian mixture models and corresponding posterior probabilities. Obtained root diameter versus length histograms from IJ-Rhizo were cumulated over all subsamples per plant and then discriminated into fibrous and (thick) storage roots using the Otsu segmentation method [68]. Using this diameter threshold and adopting a cylinder geometry for roots, length, volumes and diameters were computed for both root categories from diameter versus length frequency table. Estimated root volumes showed a good correspondence $\left(\mathrm{r}^{2}=0.74 ; p<0.05, \mathrm{n}=30\right)$ to root fresh weight in a test set.

\subsection{Statistical Analyses}

The data of DS were analysed by rank-based ANOVA according to the ANOVA-type statistics [69] using SAS PROC RANK and PROC MIXED with the ANOVAF option (SAS Institute 2016, Cary, NC, USA). Comparisons of means of the replicates $(n=9)$ were performed using $\chi^{2}$ test $(p<0.0001)$. Based on the multiple test procedure of comparisons of means $p$ values were adjusted according to Holm [70]. Least-squares means were normalised to interval $[0,1]$ and used for correlation analyses with means of root traits $(p<0.05)$. The data of fresh and dry weight of roots and stems $(n=9)$, total root length, root volume, root surface area, and root radius $(n=6)$ were analysed by two-way ANOVA according to a randomized complete block factorial design. Comparisons of means of the replicates were performed using Tukey's test $(p<0.05)$.

For the statistical testing of the fungal utilisation of plant-derived polysaccharides, one-way ANOVA was applied. The identification of differences among the isolates within the substrate groups was performed with Tukey test $(p<0.05)$. Analyses of variance (ANOVA) were conducted using STATISTICA 13.5 software (StatSoft Inc., Tulsa, OK, USA). 
Supplementary Materials: The following are available online at http://www.mdpi.com/2076-0817/9/6/509/s1, Figure S1: Extracellular enzymatic activity of Fusarium spp. isolates on plates. Figure S2: Typical symptoms caused by Fusarium spp. isolates on roots. Figure S3: Disease severity (DS) of roots of Asparagus officinalis. Figure S4: Disease severity of ferns of Asparagus officinalis. Figure S5: Relationship between concentration of fungal DNA in stem bases of Asparagus officinalis and root fresh weight after inoculation with Fusarium spp. Figure S6: Radius of storage and fibrous roots [mm] of Asparagus officinalis.

Author Contributions: The experiments were conceived and designed by R.D.F.-K., J.G., R.G., K.W. and R.Z. R.D.F.-K., J.G., K.W. and R.Z. performed the experiments and analysed the data. Specifically, R.D.F.-K. planned/designed the experiments; K.W. performed the mass spectrometric analysis and fungal growth assays; R.Z. performed the molecular analysis, and J.G. performed the root imaging analysis. R.D.F.-K., J.G., R.G., K.W. and R.Z. wrote the paper. All authors have read and agreed to the published version of the manuscript.

Funding: This work was financially supported by the Federal Ministry of Food and Agriculture (BMEL) of the Federal Republic of Germany and the Ministry of Science, Research and Cultural Affairs (MWFK) of the State of Brandenburg.

Acknowledgments: The technical assistance of Sabine Breitkopf, Angelika Fandrey, Mandy Heinze and Sieglinde Widiger is gratefully acknowledged. We thank Susanne Bargen (Humboldt University of Berlin, Berlin, Germany) and Christian Neubauer (University of Applied Sciences Osnabrück, Osnabrück, Germany) and Reiner Krämer (Julius Kühn Institute, Quedlinburg, Germany) for the gift of Fusarium spp. isolates. The authors thank Martin Sandmann for valuable statistic advice.

Conflicts of Interest: The authors declare that the research was conducted in the absence of any commercial or financial relationships that could be construed as a potential conflict of interest.

\section{References}

1. Grogan, R.G.; Kimble, K.A. The association of Fusarium wilt with the asparagus decline and replant problem in California. Phytopathology 1959, 49, 122-125.

2. Elmer, W.H. Combining nonpathogenic strains of Fusarium oxysporum with sodium chloride to suppress Fusarium crown rot of asparagus in replanted fields. Plant Pathol. 2004, 53, 751-758. [CrossRef]

3. Elmer, W.H. Fusarium diseases of asparagus. In Fusarium: Ecology, Biology E Genetics, Paul E. Nelson Memorial Symposium; Summerell, B.A., Leslie, J.F., Backhouse, D., Bryden, W.L., Burgess, L.W., Eds.; APS Press: St. Paul, MN, USA, 2001; pp. 248-262.

4. Schreuder, W.; Lamprecht, S.C.; Marasas, W.F.O.; Calitz, F.J. Pathogenicity of three Fusarium species associated with asparagus decline in South Africa. Plant Dis. 1995, 79, 177-181. [CrossRef]

5. Vujanovic, V.; Hamel, C.; Yergeau, E.; St-Arnaud, M. Biodiversity and biogeography of Fusarium species from northeastern North American asparagus fields based on microbiological and molecular approaches. Microb. Ecol. 2006, 51, 242-255. [CrossRef] [PubMed]

6. Weber, Z.; Kostecki, M.; von Bargen, S.; Gossmann, M.; Waskiewicz, A.; Bocianowski, J.; Knaflewski, M.; Büttner, C.; Golinski, P. Fusarium Species Colonizing Spears and Forming Mycotoxins in Field Samples of Asparagus from Germany and Poland. J. Phytopathol. 2006, 154, 209-216. [CrossRef]

7. Borrego-Benjumea, A.; Basallote-Ureba, M.J.; Melero-Vara, J.M.; Abbasi, P.A. Characterization of Fusarium isolates from asparagus fields in southwestern Ontario and influence of soil organic amendments on Fusarium crown and root rot. Phytopathology 2014, 104, 403-415. [CrossRef] [PubMed]

8. Elmer, W.H. Management of Fusarium crown and root rot of asparagus. Crop Prot. 2015, 73, 2-6. [CrossRef]

9. Baayen, R.P.; O'Donnell, K.; Bonants, P.J.; Cigelnik, E.; Kroon, L.P.; Roebroeck, E.J.; Waalwijk, C. Gene genealogies and AFLP analyses in the Fusarium oxysporum complex identify monophyletic and nonmonophyletic formae speciales causing wilt and rot disease. Phytopathology 2000, 90, 891-900. [CrossRef] [PubMed]

10. Fravel, D.; Olivain, C.; Alabouvette, C. Fusarium oxysporum and its biocontrol. New Phytol. 2003, 157, 493-502. [CrossRef]

11. Blok, W.J.; Bollen, G.J. Fungi on roots and stem bases of asparagus in the Netherlands: Species and pathogenicity. Eur. J. Plant Pathol. 1995, 101, 15-24. [CrossRef]

12. Marcellan, O.; Camadro, E.; Pontaroli, A.C. Contributions of biotechnology to asparagus breeding in Argentina. Am. J. Plant Sci. Biotech. 2010, 3, 23-30.

13. Lassaga, S.L.; Camadro, E.L.; Babinec, F.J. Assessing genetic variability for fusarium resistance in three asparagus populations with an in vitro assay. Euphytica 1998, 103, 131-136. [CrossRef] 
14. Damicone, J.P.; Manning, W.J. Avirulent strains of Fusarium oxysporum protect asparagus seedlings from crown rot. Can. J. Plant Pathol. 1982, 4, 143-146. [CrossRef]

15. He, C.Y.; Hsiang, T.; Wolyn, D.J. Induction of systemic disease resistance and pathogen defence responses in Asparagus officinalis inoculated with nonpathogenic strains of Fusarium oxysporum. Plant Pathol. 2002, 51, 225-230. [CrossRef]

16. Reid, P.E.; Constable, G.A.; Stiller, W.; Allen, S.; McNamara, G. The CSIRO Fusarium breeding program. In Field to Fashion, Proceedings of the 11th Australian Cotton Conference, Brisbane, 13-15 August 2002; Australian Cotton Growers Research Association: Orange, Australia, 2002; pp. 653-656.

17. Tu, C.C.; Cheng, Y.H.; Cheng, A.S. Recent advance in biological control of Fusarium wilt of asparagus in Taiwan. Acta Hortic. 1990, 271, 353-362. [CrossRef]

18. Blok, W.J.; Zwankhuizen, M.J.; Bollen, G.J. Biological control of Fusarium oxysporum f.sp. asparagi by applying non-pathogenic isolates of F. oxysporum. Biocontrol Sci. Technol. 1997, 7, 527-542. [CrossRef]

19. Arriola, L.L.; Hausbeck, M.K.; Rogers, J.; Safir, G.R. The effect of Trichoderma harzianum and arbuscular mycorrhizae on Fusarium root rot in asparagus. HortTechnology 2000, 10, 141-144. [CrossRef]

20. Matsubara, Y.; Ohba, N.; Fukui, H. Effect of arbuscular mycorrhizal fungus infection on the incidence of fusarium root rot in asparagus seedlings. J. Jpn. Soc. Hortic. Sci. 2001, 70, 202-206. [CrossRef]

21. Matsubara, Y.; Hasegawa, N.; Fukui, H. Incidence of Fusarium root rot in asparagus seedlings infected with arbuscular mycorrhizal fungus as affected by several soil amendments. J. Jpn. Soc. Hortic. Sci. 2002, 71, 370-374. [CrossRef]

22. Wacker, T.L.; Safir, G.R.; Stephens, C.T. Effect of Glomus fasciculatum on the growth of asparagus and the incidence of Fusarium root rot. J. Amer. Soc. Hort. Sci. 1990, 115, 550-554. [CrossRef]

23. Geiser, D.M.; del Mar Jiménez-Gasco, M.; Kang, S.; Makalowska, I.; Veeraraghavan, N.; Ward, T.J.; Zhang, N.; Kuldau, G.A.; O'Donnell, K. FUSARIUM-ID v. 1.0: A DNA sequence database for identifying Fusarium. In Molecular Diversity and PCR-detection of Toxigenic Fusarium Species and Ochratoxigenic Fungi: Under the aegis of COST Action 835 'Agriculturally Important Toxigenic Fungi 1998-2003', EU project (QLK1-CT-1998-01380) and the ISPP 'Fusarium Committee'; Mulè, G., Bailey, J.A., Cooke, B.M., Logrieco, A., Eds.; Springer: Dordrecht, The Netherlands, 2004; pp. 473-479.

24. Arif, M.; Chawla, S.; Zaidi, N.; Rayar, J.; Variar, M.; Singh, U. Development of specific primers for genus Fusarium and F. solani using rDNA sub-unit and transcription elongation factor (TEF-1 $\alpha$ ) gene. Afr. J. Biotechnol. 2012, 11, 444-447.

25. Zarrin, M.; Ganj, F.; Faramarzi, S. Development of a polymerase chain reaction-restriction fragment length polymorphism method for identification of the Fusarium genus using the transcription elongation factor- $1 \alpha$ gene. Biomed. Rep. 2016, 5, 705-708. [CrossRef] [PubMed]

26. Mulè, G.; Susca, A.; Stea, G.; Moretti, A. A species-specific PCR assay based on the calmodulin partial gene for identification of Fusarium verticillioides, F. proliferatum and F. subglutinans. Eur. J. Plant Pathol. 2004, 110, 495-502. [CrossRef]

27. Mulè, G.; Susca, A.; Stea, G.; Moretti, A. Specific detection of the toxigenic species Fusarium proliferatum and F. oxysporum from asparagus plants using primers based on calmodulin gene sequences. FEMS Microbiol. Lett. 2004, 230, 235-240. [CrossRef]

28. Yergeau, E.; Filion, M.; Vujanovic, V.; St-Arnaud, M. A PCR-denaturing gradient gel electrophoresis approach to assess Fusarium diversity in asparagus. J. Microbiol. Methods 2005, 60, 143-154. [CrossRef] [PubMed]

29. Wong, J.Y.; Jeffries, P. Diversity of pathogenic Fusarium populations associated with asparagus roots in decline soils in Spain and the UK. Plant Pathol. 2006, 55, 331-342. [CrossRef]

30. Corpas-Hervias, C.; Melero-Vara, J.M.; Molinero-Ruiz, M.L.; Zurera-Muñoz, C.; Basallote-Ureba, M.J. Characterization of isolates of Fusarium spp. obtained from asparagus in Spain. Plant Dis. 2006, 90, 1441-1451. [CrossRef]

31. Rafique, K.; Kang, S.; Aziz-ud-Din; Mahmood, T.; Imran; Ullah, I.; Mahmood, H. First report of Vascular Wilt on Lentil (Lens culinaris Medikus) Caused by Fusarium redolens in Pakistan. Plant Dis. 2020. [CrossRef]

32. Huisman, O.C. Interrelations of root growth dynamics to epidemiology of root-invading fungi. Annu. Rev. Phytopathol. 1982, 20, 303-327. [CrossRef]

33. Buhtz, A.; Hohe, A.; Schwarz, D.; Grosch, R. Effects of Verticillium dahliae on tomato root morphology considering plant growth response and defense. Plant Pathol. 2016, 66. [CrossRef] 
34. Morauf, C.; Steinkellner, S. Fusarium oxysporum f. sp. lycopersici and compost affect tomato root morphology. Eur. J. Plant Pathol. 2015, 143, 385-398. [CrossRef]

35. Wei, J.; Carroll, R.J.; Harden, K.K.; Wu, G. Comparisons of treatment means when factors do not interact in two-factorial studies. Amino Acids 2012, 42, 2031-2035. [CrossRef] [PubMed]

36. Patz, S.; Witzel, K.; Scherwinski, A.-C.; Ruppel, S. Culture dependent and independent analysis of potential probiotic bacterial genera and species present in the phyllosphere of raw eaten produce. Int. J. Mol. Sci. 2019, 20, 3661. [CrossRef] [PubMed]

37. Kemptner, J.; Marchetti-Deschmann, M.; Mach, R.; Druzhinina, I.S.; Kubicek, C.P.; Allmaier, G. Evaluation of matrix-assisted laser desorption/ionization (MALDI) preparation techniques for surface characterization of intact fusarium spores by MALDI linear time-of-flight mass spectrometry. Rapid Commun. Mass Spectrom. 2009, 23, 877-884. [CrossRef] [PubMed]

38. Marchetti-Deschmann, M.; Winkler, W.; Dong, H.J.; Lohninger, H.; Kubicek, C.P.; Allmaier, G. Using spores for Fusarium spp. classification by MALDI-based intact cell/spore mass spectrometry. Food Technol. Biotechnol. 2012, 50, 334-342.

39. Wigmann, É.F.; Behr, J.; Vogel, R.F.; Niessen, L. MALDI-TOF MS fingerprinting for identification and differentiation of species within the Fusarium fujikuroi species complex. Appl. Microbiol. Biotechnol. 2019, 103, 5323-5337. [CrossRef]

40. Santos, C.; Ventura, J.A.; Lima, N. New insights for diagnosis of pineapple fusariosis by MALDI-TOF MS technique. Curr. Microbiol. 2016, 73, 206-213. [CrossRef]

41. Zhao, Z.T.; Liu, H.Q.; Wang, C.F.; Xu, J.R. Comparative analysis of fungal genomes reveals different plant cell wall degrading capacity in fungi. BMC Genom. 2013, 14, 15. [CrossRef]

42. Ruiz, G.B.; Di Pietro, A.; Roncero, M.I.G. Combined action of the major secreted exo- and endopolygalacturonases is required for full virulence of Fusarium oxysporum. Mol. Plant Pathol. 2016, 17, 339-353. [CrossRef]

43. Jaroszuk-Ściseł, J.; Kurek, E.; Słomka, A.; Janczarek, M.; Rodzik, B. Activities of cell wall degrading enzymes in autolyzing cultures of three Fusarium culmorum isolates: Growth-promoting, deleterious and pathogenic to rye (Secale cereale). Mycologia 2011, 103, 929-945. [CrossRef]

44. Jaroszuk-Ściseł, J.; Kurek, E. Hydrolysis of fungal and plant cell walls by enzymatic complexes from cultures of Fusarium isolates with different aggressiveness to rye (Secale cereale). Arch. Microbiol. 2012, 194, 653-665. [CrossRef] [PubMed]

45. Elmer, W.H.; Stephens, C.T. Classification of Fusarium oxysporum f. sp. asparagi into vegetatively compatible groups. Phytopathology 1989, 79, 88-93. [CrossRef]

46. Nahiyan, A.S.M.; Boyer, L.R.; Jeffries, P.; Matsubara, Y.-i. PCR-SSCP analysis of Fusarium diversity in asparagus decline in Japan. Eur. J. Plant Pathol. 2011, 130, 197-203. [CrossRef]

47. Yadeta, K.; Thomma, B. The xylem as battleground for plant hosts and vascular wilt pathogens. Front. Plant Sci. 2013, 4. [CrossRef]

48. Wu, S.W.; Wang, H.W.; Yang, Z.D.; Kong, L.R. Expression comparisons of pathogenesis-related (PR) genes in wheat in response to infection/infestation by fusarium, yellow dwarf virus (YDV) aphid-transmitted and hessian fly. J. Integr. Agric. 2014, 13, 926-936. [CrossRef]

49. Camm, E.L.; Towers, G.H.N. Phenylalanine ammonia lyase. Phytochemistry 1973, 12, 961-973. [CrossRef]

50. Çakır, B.; Gül, A.; Yolageldi, L.; Özaktan, H. Response to Fusarium oxysporum f.sp. radicis-lycopersici in tomato roots involves regulation of SA- and ET-responsive gene expressions. Eur. J. Plant Pathol. 2014, 139, 379-391. [CrossRef]

51. Crosby, K.M. Impact of Monosporascus cannonballus on root growth of diverse melon varieties and their F1 progeny inthe field. Subtrop. Plant Sci. 2000, 52, 8-11.

52. Cichy, K.A.; Snapp, S.S.; Kirk, W.W. Fusarium root rot incidence and root system architecture in grafted common bean lines. Plant Soil 2007, 300, 233-244. [CrossRef]

53. Kraft, J.M.; Boge, W. Root characteristics in pea in relation to compaction and Fusarium root rot. Plant Dis. 2001, 85, 936-940. [CrossRef] [PubMed]

54. Arias, M.M.D.; Leandro, L.F.; Munkvold, G.P. Aggressiveness of Fusarium species and impact of root infection on growth and yield of soybeans. Phytopathology 2013, 103, 822-832. [CrossRef]

55. Elmer, W. Asparagus decline and replant problem: A look back and a look forward at strategies for mitigating losses. Acta Hortic. 2017, 1223, 195-204. [CrossRef] 
56. Guo, J.; Jermyn, W.A.; Turnbull, M.H. Diurnal and seasonal photosynthesis in two asparagus cultivars with contrasting yield. Crop Sci. 2002, 42, 399-405. [CrossRef]

57. Waśkiewicz, A.; Irzykowska, L.; Karolewski, Z.; Bocianowski, J.; Goliński, P.; Weber, Z. Mycotoxins biosynthesis by Fusarium oxysporum and F. proliferatum isolates of asparagus origin. J. Plant Prot. Res. 2009, 49, 3699. [CrossRef]

58. Shi, W.; Tan, Y.; Wang, S.; Gardiner, D.M.; De Saeger, S.; Liao, Y.; Wang, C.; Fan, Y.; Wang, Z.; Wu, A. Mycotoxigenic potentials of Fusarium species in various culture matrices revealed by mycotoxin profiling. Toxins 2016, 9, 6. [CrossRef]

59. Knaflewski, M.; Golinski, P.; Kostecki, M.; Waskiewicz, A.; Weber, Z. Mycotoxins and mycotoxin-producing fungi occurring in asparagus spears. Acta Horticulturae 2008, 776, 183-191. [CrossRef]

60. Waśkiewicz, A.; Irzykowska, L.; Bocianowski, J.; Karolewski, Z.; Kostecki, M.; Weber, Z.; Goliński, P. Occurrence of Fusarium fungi and mycotoxins in marketable asparagus spears. Polish J. Environ. Stud. 2010, 19, 219-225.

61. Ismaiel, A.A.; Papenbrock, J. Mycotoxins: Producing fungi and mechanisms of phytotoxicity. Agriculture 2015, 5, 492-537. [CrossRef]

62. Perincherry, L.; Lalak-Kańczugowska, J.; Stẹpień, Ł. Fusarium-produced mycotoxins in plant-pathogen interactions. Toxins 2019, 11, 664. [CrossRef]

63. Ferreira, L.; Sánchez-Juanes, F.; Muñoz-Bellido, J.L.; González-Buitrago, J.M. Rapid method for direct identification of bacteria in urine and blood culture samples by matrix-assisted laser desorption ionization time-of-flight mass spectrometry: Intact cell vs. extraction method. Clin. Microbiol. Infect. 2011, 17, 1007-1012. [CrossRef]

64. Feller, C.; Richter, E.; Smolders, T.; Wichura, A. Phenological growth stages of edible asparagus (Asparagus officinalis): Codification and description according to the BBCH scale. Ann. Appl. Biol. 2012, 160, 174-180. [CrossRef]

65. Leslie, J.F.; Summerell, B.A. (Eds.) The Fusarium Laboratory Manual; Blackwell Publishing Professional: Ames, IA, USA, 2006.

66. Ruijter, J.M.; Ramakers, C.; Hoogaars, W.M.; Karlen, Y.; Bakker, O.; van den Hoff, M.J.; Moorman, A.F. Amplification efficiency: Linking baseline and bias in the analysis of quantitative PCR data. Nucleic Acids Res. 2009, 37, e45. [CrossRef] [PubMed]

67. Pierret, A.; Gonkhamdee, S.; Jourdan, C.; Maeght, J.-L. IJ_Rhizo: An open-source software to measure scanned images of root samples. Plant Soil 2013, 373, 531-539. [CrossRef]

68. Otsu, N. A threshold selection method from gray-level histograms. IEEE Trans. Syst. Man Cybern. 1979, 9, 62-66. [CrossRef]

69. Brunner, E.; Munzel, U. Nichtparametrische Datenanalyse; Springer Spektrum Berlin: Berlin, Germany, 2013.

70. Holm, S. A simple sequentially rejective multiple test procedure. Scand. J. Stat. 1979, 6, 65-70. 